Proceedings

\title{
The Information Development Process of Wintersweet, Orchid, Bamboo, and Chrysanthemum in Chinese Traditional Painting from the Perspective of Information Philosophy, Also on the Selection of Chinese Traditional Painting Materials ${ }^{\dagger}$
}

\author{
Jian Cheng \\ School of Humanities and Social Sciences, Xi'an Jiaotong University, Xi'an 710049, China; \\ cjdtc123@mail.xjtu.edu.cn; Tel.: +86-1370-914-6610 \\ † The Fourth International Conference on Philosophy of Information, Berkeley, CA, USA, 2-6 June 2019. \\ Published: 25 May 2020
}

\begin{abstract}
The selection of traditional Chinese painting materials is often accompanied by other meanings given by people, and the process of giving meaning is the process of information development. Wintersweet, orchid, bamboo, and chrysanthemum, from their own form and people's observation of them, have been given a special meaning: wintersweet, proud like snow and decent people; orchid, symbolizing the gentleman's integrity and independence; bamboo, symbolizing the gentleman's humility; chrysanthemum, symbolizing the gentleman's hidden inner world, which is not trapped in the trivial things. This development process deals with the development process of in-itself information, for-itself information, and regenerated information. The wintersweet, orchid, bamboo, and chrysanthemum expressed by the artist in Chinese traditional painting is the social information of the three states of in-itself information, for-itself information, and regenerated information of three-state information. The selection of traditional Chinese painting materials has gone through the same process.
\end{abstract}

Keywords: information; traditional Chinese painting materials; information development process; Wintersweet; orchid; bamboo and chrysanthemum

\section{Philosophy of Information by Kun Wu}

The interpretation of information must be defined before the article. In the world of information philosophy construction, existence is not composed of objective existence and subjective existence, but by material and indirect existence, which is information [1].

As shown in Figure 1, the existence on the left is divided by the existence considered in traditional philosophy, while the existence on the right is the existence of information philosophy (black), which is composed of material and indirect existence of information. Information is composed of objective reality in combination with subjective existence (mind) or subjective unreality. Weiner once stressed that "information is information, not matter, not energy" [2]. In summary, information is a philosophical category that marks the indirect existence of matter, and it is the selfdisplay of the way and state of material existence. The concept of information provides an indirect field of connection between objective existence and subjective existence in traditional philosophy, which is also the research field and starting point of information philosophy. 


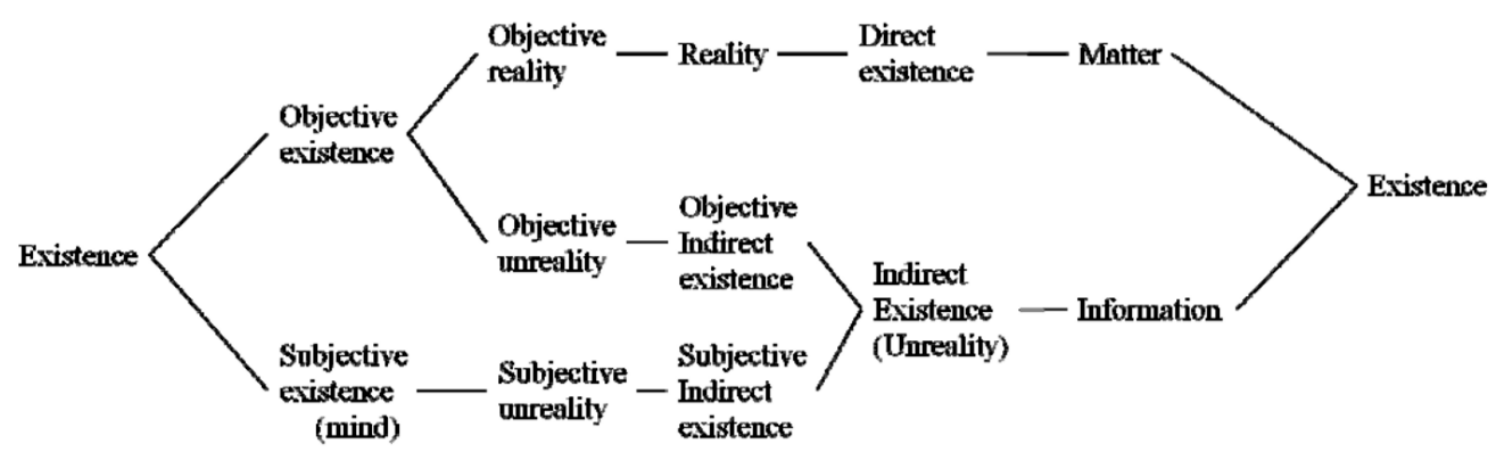

Figure 1. Division of areas of existence.

The study of traditional Chinese painting materials in this paper is based on the restructure of information philosophy around the existence of objective indirect existence and subjective existence (mind).

Professor Kun $\mathrm{Wu}$ has defined for us that information is a philosophical category that marks the indirect existence of matter-it is the display of the way and state of existence of matter (direct existence) and, from the point of view of the process of production, indirect existence can only be produced in the interaction of direct existence. Once indirect existence occurs, it surpasses the direct nature with its own unique characteristics, and at the same time unfolds its own movement and development process. In this course, the information presents its own different forms and forms. The different forms and forms of information are specific to in-itself information, for-itself information, regenerated information, and social information.

\section{The Information Development Process of Four Gentlemen}

"Four gentlemen" is the subject of traditional Chinese paintings - wintersweet, orchid, bamboo, and chrysanthemum are called the "four gentlemen". The selection of traditional Chinese painting materials is often accompanied by other meanings given by people, and the process of giving meaning is the process of information development.

In-itself information is a sign of objective and indirect existence, and the original form of information that has not yet been grasped and recognized by the subject. Its identification is first and foremost through the information field it produces to show itself. For example, wintersweet, orchid, bamboo, and chrysanthemum are the respective forms of their own externalization in the information field domain and other points of difference so that they stand out. Wintersweet's flower season is in winter, orchids are often found in the deep valley, bamboo grows in the sky straight, and chrysanthemum's deep autumn bloom-these differences make their own characteristics of information attributes.

For-itself information is based on the human nervous system. Through perception, the subject of information visual identification, and memory, the body storage of information, information develops from the in-itself stage to for-itself stage. Wintersweet, orchid, bamboo, and chrysanthemum's own self-contained information properties rise from self-contained with the help of the information control systems of perception and sensory memory. In this way, wintersweet, orchid, bamboo, and chrysanthemum, in their own development of a certain stage, gave themselves a self-conscious quality. This quality, through the material movement itself, displayed information in a specific information body for identification and recallable storage. Based on this, wintersweet, orchid, bamboo, and chrysanthemum's information will continue to carry out its own subjective reprocessing and retransformation processes, so that wintersweet, orchid, bamboo, and chrysanthemum's physical states reach the spiritual level.

Regenerated information is an advanced stage of subjective indirect existence and a creative form of the subject of information. People's transformation of natural energy is such that the information for the human brain to perceive and remember can be transformed by analysis and 
integrated processing, creating new information, which reacts to the results of nature. Its basic form is general information, symbolic information and inspiration, and intuition (symbol information and inspiration and intuition and relevance are less relevant to this article). In the process of thinking, we use the appearance of perceptual memory to create a new image, then we call this thought process the image of the process, and this created new image is called the image information. Wintersweet, orchid, bamboo, and chrysanthemum's unique differences from the traditional understanding of Chinese, combined with the main body of information creation, form the image of wintersweet, orchid, bamboo, and chrysanthemum information: Wintersweet flourishes in the winter with heavy snow and it is not afraid of the cold-it means being proud like snow and decent people. The orchid develops alone in the valley, enjoying the cliffs and deep valleys, symbolizing the gentleman's integrity and independence. The bamboo is empty in the inside and straight on the outside, elegant and beautiful, symbolizing the gentleman's humility. The chrysanthemum blooms in the late autumn. In the wind, it is so elegant, symbolizing the gentleman's hidden inner world, which is not trapped in the trivial things. The visual identification of the "four gentlemen" information and the storage of impressionable memory are created through the main body of information, forming the general information, and people raise them to a spiritual quality through the visual grasp of the subject of information, respectively: proud, claustrophobic, elegant, and easy. Their meanings are: wintersweet, proud like snow and decent people; orchid, symbolizing the gentleman's integrity and independence; bamboo, symbolizing the gentleman's humility; and chrysanthemum, symbolizing the gentleman's hidden inner world, which is not trapped in the trivial things.

Social information is a kind of information phenomenon presented in the relationship between self-contained, self-contained, and regenerative three-state information. In the participation of human consciousness, the interaction between man and nature and man and man, information is always in the human class and human consciousness, and human dependence on the natural environment of the three constitute the whole system unified. This whole system is the society, in which the unity of the three-state information displayed is the social information [3]. For the understanding of social information, the wintersweet, orchid, bamboo, and chrysanthemum examples are still applicable, as the artist's creation of the art material "four gentlemen" combined with the subjective identification of information and the main body creation, forming an overview of information and symbolic information, and through the expression of rich artistic techniques emphasize its proud, claustrophobic, elegant, and easy quality characteristics. After this, artistic creation shows that the wintersweet, orchid, bamboo, and chrysanthemum can also be called regeneration information. In short, the objective indirect existence of wintersweet, orchid, bamboo, and chrysanthemum's own image is for in-itself information; how people perceive wintersweet, orchid, bamboo, and chrysanthemum is for-self information; how people feel the spirit of the four gentlemen is the regeneration of information, and the artist's creation which contains the form and the artistic performance of wintersweet, orchid, bamboo, and chrysanthemum as well as the spirit of them, embodies the regeneration information.

Wintersweet, orchid, bamboo, and chrysanthemum develop from their own form, to the human observation, to people give them special meaning. This development process deals with the development process of in-itself information, for-itself information, and regenerated information. The wintersweet, orchid, bamboo, and chrysanthemum expressed by the artist in Chinese traditional painting is the social information of the three states of self-contained, self-contained, and regenerative three-state information. The selection of traditional Chinese painting materials has gone through the same process. As the unity of social information, this may also be why an important occasion like the Great Hall of the People requires huge paintings with the attributes of social information rather than a photography work that is intuitively displayed for self-expression of information. It must be mentioned that while ordinary painters (provided that the painter has mastered the basic expression of the artist) painted, rewriting is still only stuck in the level of self-information. This also shows how the level of painting also reflects the artist's grasp and understanding of the process of information development. Western painters, in the nearly hundred years of development, are only gradually becoming aware of their innate shortcomings. 


\section{Conclusions}

Chinese painting and western paintings are different from realism, and the mood emphasized by painting is explained by the expression of this information. Chinese painting has been accompanied by people's pursuit of the subject consciousness of painting art materials since ancient times. It is not a direct and simple response to an objective object.

Chinese traditional painting does not rewrite the reality, while the western traditional painting rewrites the real. The traditional Chinese painting emphasizes the mood that is being explained by the expression of this information. Chinese traditional painting has been accompanied by people's pursuit of the subject consciousness of painting art materials since ancient times, and it is not a direct and simple response to objective objects. The process of examining the selection and development of traditional Chinese painting material from the perspective of information philosophy explains the reasons for the different selection materials of Chinese and western paintings (western painting has only begun to wade into the subject matter of landscape in recent decades) and the differences in the spiritual grasp of the subjects of Chinese and western paintings. Traditional Chinese painting has long transcended the grasp of shape, and then developed into the further development and extension of the "information" behind it. The author of the theory of information form and information form development, Professor Kun $\mathrm{Wu}$, also pointed out the direction of the development of personal painting art for the painters of the new era.

Funding: This research was funded by National Social Science Fund, grant number 18ZDA027.

Conflicts of Interest: The author declares no conflict of interest.

\section{References}

1. Wu, K. Philosophy of Information: Theory, System and Method; The Commercial Press: Beijing, China, 2005; p. 47.

2. Wiener, N. Cybernetics; Hao, J., Trans.; Science Press: Beijing, China, 2017; p. 133.

3. Wu, K. Philosophy of Information: Theory, System and Method; The Commercial Press: Beijing, China, 2005; p. 58.

(C) 2020 by the authors. Licensee MDPI, Basel, Switzerland. This article is an open access article distributed under the terms and conditions of the Creative Commons Attribution (CC BY) license (http://creativecommons.org/licenses/by/4.0/). 